\title{
Behavioural responses of young anaemic Indian children to iron-folic acid supplements
}

\author{
By SUBADRA SESHADRI, KALPANA HIRODE, PALLAVI NAIK \\ AND SWATI MALHOTRA \\ Department of Foods and Nutrition, M. S. University of Baroda, Baroda 390002 , \\ Gujarat, India
}

(Received 15 May 1981-Accepted 23 March 1982)

1. Behavioural responses of young anaemic Indian children to iron-folic acid supplements were assessed in two separate studies using the Indian adaptation of Wechsler's (1967) intelligence scale for children (WISC).

2. The first study was an exploratory study in which the cognitive behaviour of 5-8-year-old children of both sexes was assessed before and after supplementation with $20 \mathrm{mg}$ elemental $\mathrm{Fe}$ and $0.1 \mathrm{mg}$ folic acid given daily for a period of $60 \mathrm{~d}$.

3. The supplemented children showed a significant improvement in haemoglobin ( $\mathrm{Hb})$ as well as the WISC scores while the control children who did not receive any supplements failed to show an improvement either in $\mathrm{Hb}$ or in the WISC scores. However, within the supplemented group when the initially-anaemic children were compared with the initially-non-anaemic ones, only the 7-year-old anaemic children performed significantly poorer in the tests than the non-anaemic group of the same age. The study raised the possibility that in addition to increasing the blood Hb levels, Fe-folic acid supplements may have additional benefits in improving the cognitive performance of children.

4. In the second study, cognitive behaviour of fourteen matched pairs of anaemic children in the age-range of 5-6 years was assessed before and after supplementation with $40 \mathrm{mg}$ Fe and $0.2 \mathrm{mg}$ folic acid given daily in two divided doses or sugar placebos for a period of $60 \mathrm{~d}$. The tester did not know the group to which each child belonged.

5. The supplemented children showed a significant improvement in $\mathrm{Hb}$ as well as in the verbal and performance IQ of WISC. The control children showed no improvement in Hb but their verbal IQ improved significantly. However, there was no significant improvement in their performance IQ.

6. The results indicated that Fe-folic acid supplements to anaemic children not only raised Hb levels but also improved intelligence test results, particularly in the performance section.

Nutritional anaemia and particularly iron-deficiency anaemia is highly prevalent in India and other developing countries (WHO, 1975). Although observations such as apathy, irritability and lack of concentration have been made in anaemic subjects, it is only recently that scientific documentation about the deleterious effects of anaemia has become available (WHO, 1975). That cognitive behaviour may be adversely affected by anaemia has been suggested by some investigators (Sulzer et al. 1973; Webb \& Oski, 1973; Pollitt et al. 1978). The implications of this for a developing country, where vast sums of money are spent on education, are important. However, reported studies on anaemia and educational achievement have come primarily from the developed countries, with no information available on children in developing countries. Hence, we have assessed the cognitive behaviour of young children in two separate studies, before and after oral Fe-folic acid supplements, the results of which are reported here.

\section{METHODS AND MATERIALS}

\section{Subjects}

Expt 1. The subjects were ninety-four children of both sexes in the age-group 5-8 years, all from a low socio-economic group. The children were stratified by age and within each age-group, every third child was randomly assigned to the control group and the other two 
to the experimental group. The experimental children were given $20 \mathrm{mg} \mathrm{Fe}$ and $0 \cdot 1 \mathrm{mg}$ folic acid daily for a period of $60 \mathrm{~d}$ in the form of a sugar-coated tablet. The control children did not receive any supplements.

Expt 2. Sixty boys, all from a low socio-economic group and in the age-range 5-6 years, were screened for height, weight, haemoglobin $(\mathrm{Hb})$, erythrocyte morphology and 'drawa-man'-IQ (DAM-IQ; Goodenough, 1926). Of these fourteen pairs of children were selected to comprise the final sample. The criteria for selection were: $\mathrm{Hb} 80-105 \mathrm{~g} / \mathrm{l}$, microcytic hypochromic erythrocyte morphology, weight-for-age above $60 \%$ of the Harvard standards (Vaughan, 1975) and DAM-IQ above 70. The children in each pair were matched as closely as possible for the previously-mentioned criteria as well as for mother's education and per capita income. One child from each pair was randomly assigned to the control group by tossing a coin and the other to the experimental group. The experimental children were given two tablets of Fe-folic acid daily for a period of $60 \mathrm{~d}$. Each tablet consisted of $20 \mathrm{mg} \mathrm{Fe}$ and $0 \cdot 1 \mathrm{mg}$ folic acid. The controls received sugar placebos.

\section{Experimental procedure}

Initial values for height, weight, $\mathrm{Hb}$ and scores on psychological test were collected for all children in both the experiments. At the end of the period of supplementation values were obtained for $\mathrm{Hb}$ and psychological test performance. Additionally, in Expt 2 erythrocyte morphology was assessed initially.

\section{Height, weight, $\mathrm{Hb}$ and erythrocyte morphology}

Heights and weights were recorded using standard procedures (Jelliffe, 1966).

$\mathrm{Hb}$ estimations were carried out by the oxyhaemoglobin method in Expt 1 and by the cyanmethaemoglobin method in Expt 2, in both instances using a photoelectric colorimeter (Dacie \& Lewis, 1977). Erythrocyte morphology was assessed from a thin blood smear stained with Leishman's stain (Dacie \& Lewis, 1977).

\section{Psychological testing}

'Draw-a-man' (Goodenough, 1926) test adapted to Indian children by Phatak (1966) was used to screen children for their initial IQ. Cognitive behaviour before and after supplementation period was assessed using the Indian adaptation of Wechsler's (1967) intelligence scale for children (WISC): this battery of tests consisting of six verbal and six performance tests was adapted for Gujarati children by Bhatt (1973). The procedure was standardized with Gujarati children, primarily of the middle- and low-income groups. In the present study the tests were administered in Gujarati, the native language of the children. (There is also provision to administer the test in Hindi and English.) In the second experiment the psychological test was conducted by an investigator who did not know to which group the children belonged.

\section{Statistical analysis}

The differences between the initial and final values for $\mathrm{Hb}$ and WISC scores were analyzed by the paired $t$ test. For all other comparisons Student's $t$ test was used (Snedecor \& Cochran, 1969).

\section{RESULTS AND DISCUSSION}

Expt 1. Analysis of the initial height and weight of the children showed that there was no difference between the experimental and control groups. All children had weight-for-age above $60 \%$ of the Harvard standards (Vaughan, 1975). The mean height and weight of children in the present study were slightly higher than the average values reported by the 


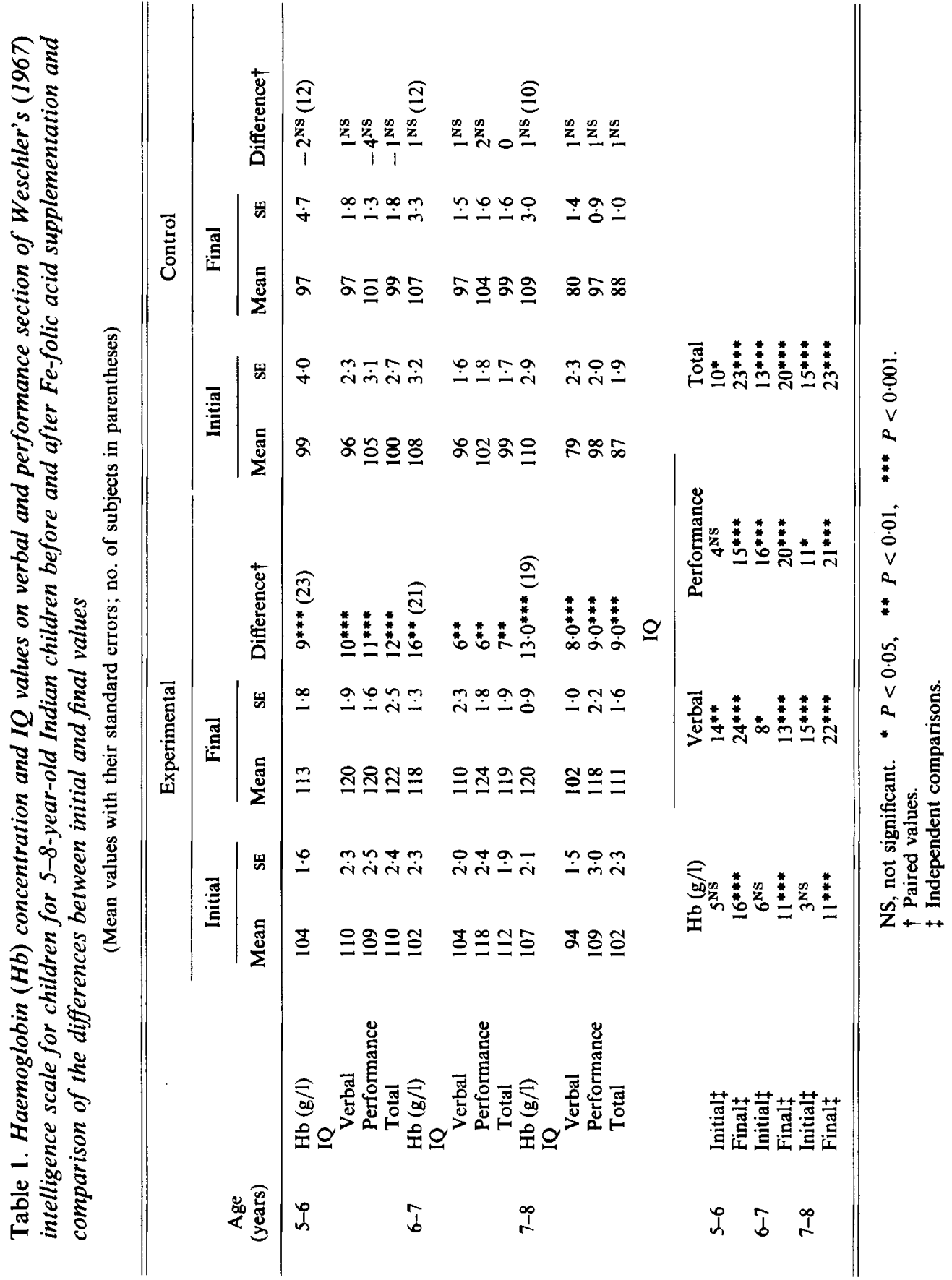


Indian Council of Medical Research (1972) for Indian children of mixed socio-economic status. The $\mathrm{Hb}$ and test scores before and after supplementation are shown in Table 1 . The supplemented children showed a significant $(P<0.001)$ increase in $\mathrm{Hb}$ while the control children showed no change. There was also a significant $(P<0.01)$ improvement in the verbal and performance IQs of the supplemented children while the control children scored approximately the same before and after the placebo treatment period. Thus it appeared that with an increase in blood $\mathrm{Hb}$, cognitive performance also improved significantly. However, interpretation of this finding was subject to a number of difficulties, some of them associated with the experimental design. Being an exploratory study, it was not designed as a blind trial, and that raised the possibility of investigator bias. The control children were not given placebos which may have resulted in effects similar to the Hawthorne effect (Selltiz et al. 1959). Further, the initial verbal and performance IQs of the control children were significantly inferior to that of the experimental children, the only exception being the performance IQ of the 5-6-year-old control children (Table 1). In order to deal with this disparity, the initially low-and high-IQ experimental children were analysed separately. These results are shown in Table 2. As can be seen, even the initially-low-IQ children in the experimental group had shown a significant improvement in the verbal and performance IQs.

An attempt was then made to analyse the test scores of the experimental children by classifying the children into anaemic and non-anaemic on the basis of their initial $\mathrm{Hb}$ values using the WHO (1975) criterion. The results were inconsistent (Table 3). The initial scores for the anaemic children were significantly $(P<0.05)$ lower than those for non-anaemic only in the 7-8 years age-group. Improvements in test scores on supplementation followed a similar trend, i.e. only the anaemic 7-8-year-old children showed a greater improvement in the test scores on supplementation than the non-anaemic children of the same age. The only general and consistent trend was that some improvement occurred in the cognitive performance of children as a result of supplementation which ranged from 4 to 13 points.

Expt 2. The problems encountered in the first study were corrected in the second experiment. The psychological testing was conducted by a trained investigator who did not know to which group the children belonged. The control children were given sugar placebos. Further, the children in the control group were initially matched with the children in the experimental group on the basis of their DAM-IQ.

Table 4 shows the initial values for age, height, weight, DAM-IQ and per capita income of the experimental and control children. None of these was different between the two groups.

The $\mathrm{Hb}$ and verbal and performance IQs of the children before and after the supplementation period are shown in Table 5. There was a highly significant $(P<0.001)$ improvement in the blood $\mathrm{Hb}$ of the supplemented children that averaged $24.2 \mathrm{~g} / \mathrm{l}$, while the control children had shown a slight decrease in the $\mathrm{Hb}$ which, however, was not significant. A significant improvement was noted in the verbal IQ of the experimental $(P<0.01)$ and control $(P<0.05)$ children after the period of supplementation. However, increase in the experimental group was much higher than in the control group. The performance IQ improved significantly $(P<0.01)$ only in the supplemented group. Initially, the differences in verbal and performance IQs between control and experimental groups were not significant, while at the end of the supplementation period both were significantly $(P<0.05)$ higher for the supplemented group. The total IQ of both supplemented and placebo groups showed a significant improvement, the increase in the scores being higher for the experimental $(P<0.01)$ group than for the control $(P<0.05)$ group.

The WISC sub-test profile showed that improvement in the verbal IQ of the experimental children occurred mainly due to an improvement in the information, similarities, vocabulary, 


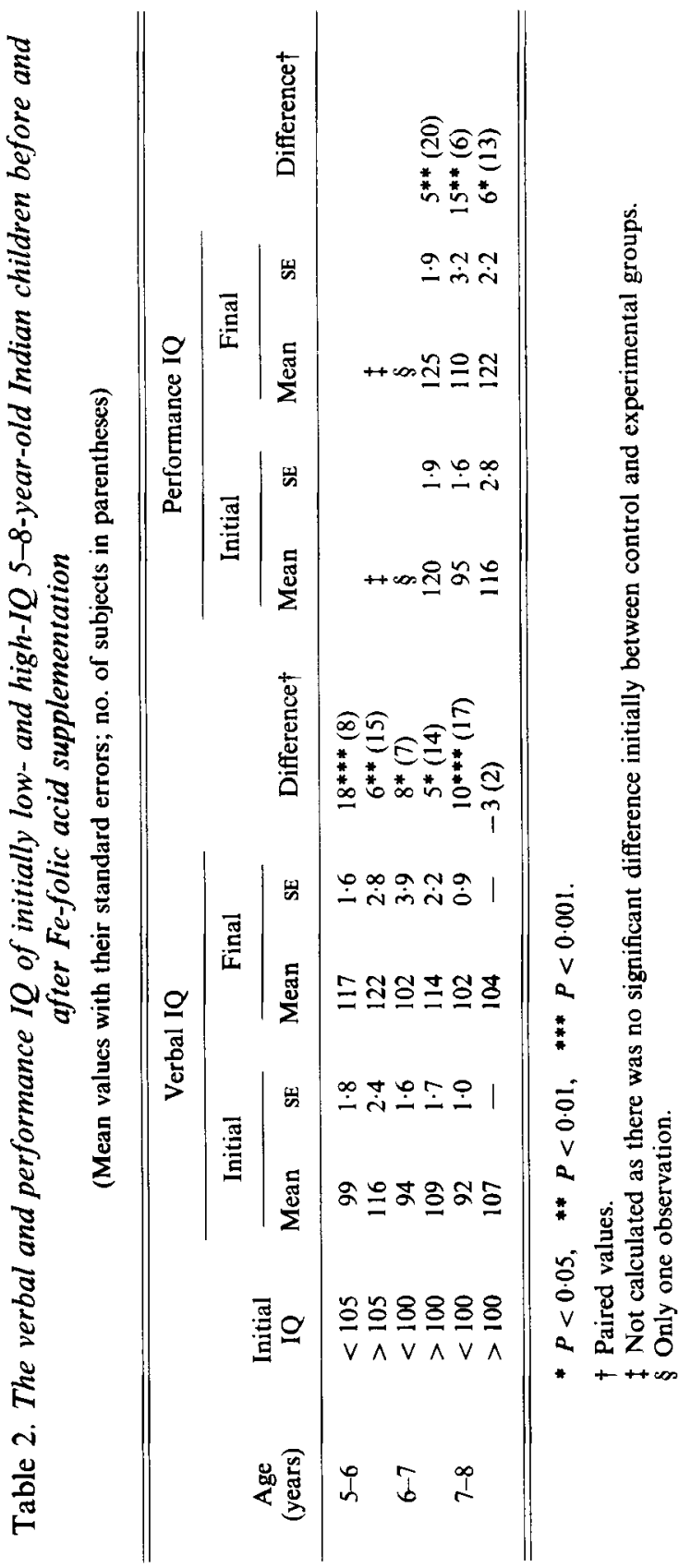




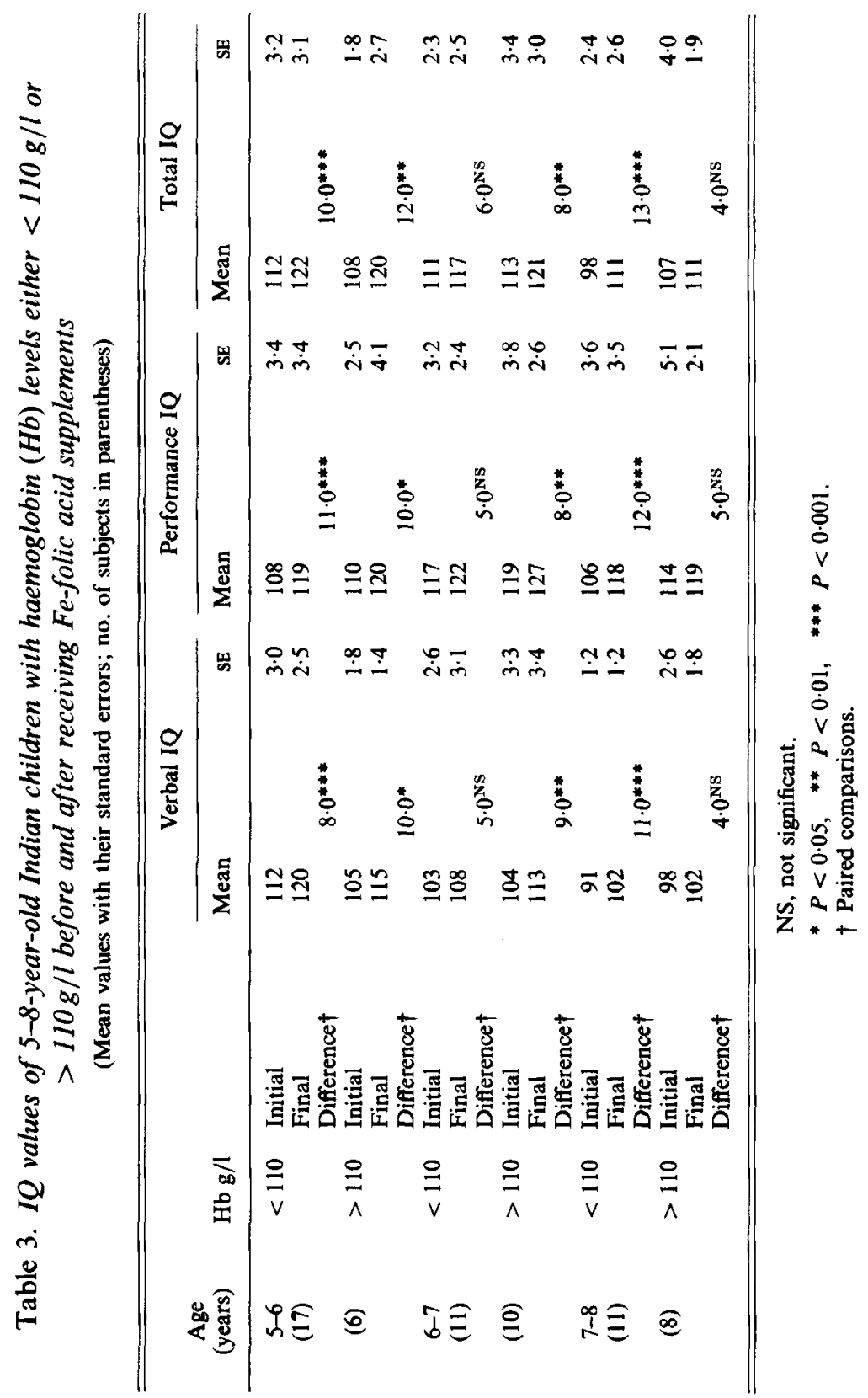


Table 4. Expt 2. Initial values for age, height, weight, 'draw-a-man' IQ (DAM-IQ; Goodenough, 1926) and per capita income of 5-6-year-old Indian children in the matched-pair study

(Mean values with their standard errors; no. of subjects in parentheses)

\begin{tabular}{|c|c|c|c|c|c|c|c|c|c|c|}
\hline \multirow[b]{2}{*}{ Group } & \multicolumn{2}{|c|}{ Age (years) } & \multicolumn{2}{|c|}{ Wt (kg) } & \multicolumn{2}{|c|}{ Height $(\mathrm{cm})$} & \multicolumn{2}{|c|}{ DAM-IQ } & \multicolumn{2}{|c|}{$\begin{array}{c}\text { Per capita } \\
\text { income } \\
\text { (Rs./month) }\end{array}$} \\
\hline & Mean & $\mathrm{SE}$ & Mean & SE & Mean & $\mathbf{S E}$ & Mean & $\mathbf{S E}$ & Mean & SE \\
\hline $\begin{array}{c}\text { Experimental } \\
\text { (14) }\end{array}$ & $5 \cdot 7$ & 0.04 & $13 \cdot 6$ & 0.33 & 101.6 & 0.82 & 86 & $2 \cdot 5$ & 42 & 1.9 \\
\hline $\begin{array}{l}\text { Control } \\
\qquad(14)\end{array}$ & 5.6 & 0.04 & $13 \cdot 4$ & 0.29 & $101 \cdot 4$ & 0.77 & 85 & 3.0 & 47 & $2 \cdot 3$ \\
\hline
\end{tabular}

Table 5. Expt 2. Haemoglobin $(H b)$ concentration and $I Q$ values on verbal and performance section of Weschler's (1967) intelligence scale for children for 5-6-year-old Indian children before and after Fe-folic acid supplementation and a comparison of the differences between experimental and control groups initially and finally on the matched-pair study

(Mean values with their standard errors; no. of subjects in parentheses)

\begin{tabular}{|c|c|c|c|c|c|c|c|c|c|c|}
\hline \multirow[b]{3}{*}{ Group } & \multicolumn{4}{|c|}{$\mathrm{Hb}(\mathrm{g} / \mathrm{l})$} & \multirow{3}{*}{$\begin{array}{c}\text { Differ- } \\
\text { ence }\end{array}$} & \multicolumn{4}{|c|}{ Verbal IQ } & \multirow{3}{*}{$\begin{array}{l}\text { Differ- } \\
\text { encet }\end{array}$} \\
\hline & \multicolumn{2}{|c|}{ Initial } & \multicolumn{2}{|c|}{ Final } & & \multicolumn{2}{|c|}{ Initial } & \multicolumn{2}{|c|}{ Final } & \\
\hline & Mean & $\mathbf{S E}$ & Mean & SE & & Mean & $\mathbf{S E}$ & Mean & SE & \\
\hline $\begin{array}{c}\text { Experimental } \\
(14)\end{array}$ & $96 \cdot 2$ & $2 \cdot 7$ & $120 \cdot 4$ & $2 \cdot 8$ & $24 \cdot 2 * * *$ & 94 & $2 \cdot 2$ & 104 & $2 \cdot 7$ & $10^{* *}$ \\
\hline $\begin{array}{l}\text { Control } \\
\text { (14) }\end{array}$ & $98 \cdot 2$ & $2 \cdot 3$ & $97 \cdot 4$ & $3 \cdot 8$ & $0.8^{\mathrm{NS}}$ & 91 & $2 \cdot 7$ & 96 & $2 \cdot 1$ & $5^{*}$ \\
\hline \multirow[t]{3}{*}{ Difference $\ddagger$} & $2^{\mathrm{NS}}$ & - & $23 * * *$ & - & - & $3^{\mathrm{NS}}$ & 一 & $8^{*}$ & - & 一 \\
\hline & \multicolumn{4}{|c|}{ Performance $1 Q$} & & \multicolumn{4}{|c|}{ Total IQ } & \\
\hline & \multicolumn{2}{|c|}{ Initial } & \multicolumn{2}{|c|}{ Final } & \multirow{2}{*}{$\begin{array}{l}\text { Differ- } \\
\text { ence } †\end{array}$} & \multicolumn{2}{|c|}{ Initial } & \multicolumn{2}{|c|}{ Final } & \\
\hline Group & Mean & $\mathrm{SE}$ & Mean & $\mathbf{S E}$ & & Mean & $\mathbf{S E}$ & Mean & SE & ence $\nmid$ \\
\hline $\begin{array}{c}\text { Experimental } \\
\text { (14) }\end{array}$ & 100 & $3 \cdot 6$ & 117 & $3 \cdot 4$ & $17^{* *}$ & 97 & $2 \cdot 9$ & 112 & 3.8 & $15^{* *}$ \\
\hline $\begin{array}{l}\text { Control } \\
\text { (14) }\end{array}$ & 98 & $3 \cdot 4$ & 104 & $3 \cdot 2$ & $6^{\mathrm{Ns}}$ & 94 & $2 \cdot 9$ & 101 & $2 \cdot 5$ & $7 *$ \\
\hline Difference $\ddagger$ & $3^{\mathrm{NS}}$ & - & $13^{*}$ & - & - & $3^{\mathrm{NS}}$ & - & $11^{*}$ & - & 一 \\
\hline
\end{tabular}

NS, not significant.

* $P<0.05$, ** $P<0.01$, *** $P<0.001$.

$\dagger$ Paired comparisons.

$\ddagger$ Independent comparisons.

arithmetic and digit span sub-tests while the control children showed an improvement only in the last two. The improvement in the performance IQ of the experimental children was accounted for by an improvement in picture arrangement, coding and mazes whereas the control children showed no significant improvement in any of these. The task demands of the performance tests in which the experimental children showed an improvement were eye-hand and visual-motor coordination as well as pencil manipulation. This suggests that improved scores in perforance IQ may be due to improved psycho-motor function. 
The results of the present studies reflects similar findings reported by other investigators. Sulzer et al. (1973) tested anaemic and normal children using a culture-free IQ test and another battery of tests which included reaction time, attentive recall and cranking tasks. The anaemic subjects were reported to have a significantly poorer performance in vocabulary tests while similar but statistically non-significant results were reported for other criteria. Webb \& Oski (1973) have also reported that anaemic adolescents had significantly lower scores in the lowa test of basic skills than the normal children of the same age. In a recent study Pollitt et al. (1978) demonstrated that Fe-deficiency in the absence of anaemia can also have adverse effects on cognitive functions. The latter authors reported that the adverse effects on attention and memory control processes in Fe-deficient preschool children (mean $\mathrm{Hb} 115.8 \mathrm{~g} / \mathrm{l}$ ) were reversed with Fe therapy. It has been suggested that Fe deficiency may produce scholastic under-achievement and behavioural disturbances in children possibly through defects in metabolism of monoamines involved in neural transmission (Pollitt \& Leibel, 1976).

The authors acknowledge gratefully the guidance received from Dr T. S. Saraswathy and Dr Veena Mistry of the Department of Child Development, M. S. University of Baroda in psychological testing. They thank Ms Neeru Mital for help in statistical analysis.

\section{REFEREN CES}

Bhatt, M. C. (1973). Gujarati Adaptation of Wechsler Intelligence Scale for Children. Ahmedabad, India: Jayashree Mudranalaya Press.

Dacie, J. V. \& Lewis, L. M. (1977). Practical Haematology, 5th ed., pp. 32, 72. Singapore: ELBS and Churchill Livingstone.

Goodenough, F. L. (1926). Measurement of Intelligence by Drawings. New York: World Book Company.

Indian Council of Medical Research. (1972). Indian Counc. med. Res. Tech. Rep. Ser. no. 18.

Jelliffe, D. B. (1966). Wld Hlth Org. Monogr. Ser. no. 53, p. 64.

Phatak, P. (1966). Draw-a-man Test for Indian Children. Baroda, India: Printrance.

Pollitt, E., Greenfield, D. \& Leibel, R. (1978). Fedn Proc. Fedn Am. Socs exp. Biol. $37,487$.

Pollitt, E. \& Leibel. R. L. (1976). J. Pediat. 88, 372.

Selltiz, C., Jahoda, M., Deutsch, M. \& Cook, S. W. (1959). Research Methods in Social Relations, p. 497. New York: Holt, Rinehart and Winston.

Snedecor, G. W. \& Cochran, W. G. (1969). Statistical Methods, 6th ed. Ames, lowa: The Iowa State University Press.

Sulzer, J. L., Wesley, H. H. \& Leonig, F. (1973). Quoted by Poilitt, E. \& Leibel, R. L. (1976). In J. Pediat. 88, 372.

Vaughan, V. C. (1975). In Textbook of Pediatrics, 10th ed., p. 41 [W. E. Nelson, V. C. Vaughan and R. J. McKay, editors]. Tokyo: Igaku Shoin Ltd.

Webb, T. E. \& Oski, F. A. (1973). Pediat. Res. 7, 294.

Wechsler, D. (1967). Wechsler Intelligence Scale for Children. New York: Psychological Corporation.

WHO (1975). Wld Hlth Org. Tech. Rep. Ser. no. 580. 